\title{
New trends in minimally invasive management of liver tumors
}

\author{
Fernando Andrés Alvarez $z^{1,2}$ \\ ${ }^{1}$ Hepato-pancreato-biliary Surgery Section, General Surgery Service, Clínica Universitaria Reina Fabiola, Córdoba 14014, \\ Argentina. \\ ${ }^{2}$ General Surgery Service, Hospital Italiano de Buenos Aires, Buenos Aires C1199ABB, Argentina.
}

Correspondence to: Dr. Fernando Andrés Alvarez, Hepato-pancreato-biliary Surgery Section, General Surgery Service, Clínica, Universitaria Reina Fabiola, Córdoba 14014, Argentina. E-mail: fernandoalvarez@curf.ucc.edu.ar

How to cite this article: Alvarez FA. New trends in minimally invasive management of liver tumors. Mini-invasive Surg 2019;3:14. http://dx.doi.org/10.20517/2574-1225.2019.11

Received: 10 Apr 2019 Accepted: 10 Apr 2019 Published: 14 May 2019

Science Editor: Fernando Andrés Alvarez Copy Editor: Cai-Hong Wang Production Editor: Huan-Liang Wu

Surgery has evolved greatly in the last decades, being the development and widespread application of minimally invasive surgery for a critical protagonist such evolution for nearly all surgical fields. In the field of hepatobiliary surgery, the introduction of new technological devices along with several improvements in anesthetic management and surgical techniques have brought us nowadays to a reality in which most patients suffering from liver tumors can safely benefit from a minimally invasive approach at some point of their treatment pathway ${ }^{[1-3]}$. For those patients who are candidates to curative intent liver resection, laparoscopic approach has gained increasing importance within modern oncological liver surgery, with recent evidence showing a faster recovery and uncompromised long-term outcomes ${ }^{[4]}$. On the other hand, minimally invasive percutaneous, endovascular or endoscopic palliation has also evolved greatly in recent years, allowing chemotherapy treatment and a better quality of life for those patients who are not up-front candidates to surgical resection ${ }^{[1-3]}$.

The aim of this Special Issue was to portray in full range the state-of-the-art minimally invasive surgical techniques that form the up-to-date armamentarium to manage patients with liver tumors. This special issue would not have been produced without the outstanding contributions of experts from Brazil, Germany, Italy and India, who present their experience and discuss topics such as minimally-invasive liver resection for liver tumors both in adults and children, quality-of-life evaluation after laparoscopic liver resections, enhanced recovery after surgery in liver resections and endoscopic ultrasound-guided drainage of the biliary tree in malignant obstructions ${ }^{[5-9]}$.

I want to express my gratitude to these authors for their time and effort in producing high-quality original manuscripts that demonstrate the many benefits of minimally invasive management of liver tumors

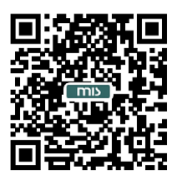


and confirm that these approaches will certainly keep developing in the years to come for the good of our patients. Finally I would like to thank the Mini-invasive Surgery Journal, its editorial Board and the Assistant Editor Ms. Anne Niu, for honoring me with the invitation to serve as Guest Editor for this Special Issue.

\section{DECLARATIONS}

Authors' contributions

Alvarez FA contributed solely to this preface.

\section{Availability of data and materials}

Not applicable.

\section{Financial support and sponsorship}

None.

\section{Conflicts of interest}

The author declared that there are no conflicts of interest.

\section{Ethics approval and consent to participate}

Not applicable.

\section{Consent for publication}

Not applicable.

\section{Copyright}

(c) The Author(s) 2019.

\section{REFERENCES}

1. de Santibañes E, Ardiles V, Alvarez F, Busnelli VC, de santibañes M. Extreme hepatic surgery and other strategies: increasing resectability in colorectal liver metastases. Springer; 2017.

2. Yohanathan L, Cleary SP. Minimally invasive management of secondary liver cancer. Surg Oncol Clin N Am 2019;28:229-41.

3. Li D, Kang J, Golas BJ, Yeung VW, Madoff DC. Minimally invasive local therapies for liver cancer. Cancer Biol Med 2014;11:217-36.

4. Wakabayashi G, Cherqui D, Geller DA, Buell JF, Kaneko H, et al. Recommendations for laparoscopic liver resection: a report from the second international consensus conference held in Morioka. Ann Surg 2015;261:619-29.

5. Kumar N, Jha SK, Negi SS. Enhanced recovery after surgery in liver surgery. Mini-invasive Surg 2018;2:41.

6. Pais-Costa SR, Teixeira Lima OA, Costa GC, Martins SJ. Laparoscopic hepatectomy for benign hepatic lesions: short and long-term outcomes including quality-of-life evaluation. Mini-invasive Surg 2018;2:33.

7. Armellini E, Mazza F, Ballarè M, Donato G, Orsello M, et al. Endoscopic ultrasound-guided drainage of the biliary tree in malignant obstruction. Mini-invasive Surg 2018;2:23.

8. Cortes-Cerisuelo M, Berger M. Minimally-invasive liver resection for liver tumors in children: a snapshot of the current landscape. Mini-invasive Surg 2019;3:1.

9. Golhar A, Nikam V, Rao P, Mohanka R. Laparoscopic resection of liver tumors. Mini-invasive Surg 2019;3:9. 